\title{
The Cure Fraction of Glioblastoma Multiforme
}

\author{
Nicolas R. Smolla, ${ }^{\text {b }}$ Karl Schaller ${ }^{b}$ Oliver P. Gautschi ${ }^{b}$ \\ ${ }^{a}$ Gippsland Medical School, Monash University, Churchill, Vic., Australia; ${ }^{b}$ Department of Neurosurgery, \\ Geneva University Medical Center, Faculty of Medicine, University of Geneva, Geneva, Switzerland
}

\section{Key Words}

Glioblastoma multiforme · Cure fraction - Relative survival • Long-term survival · Surveillance, Epidemiology and EndResults database

\begin{abstract}
Background and Purpose: This study presents a statistical model to explore the presence of a population-based cure fraction in populations with a GBM. Patients and Methods: Data for this study was obtained from the Surveillance, Epidemiology and End-Results (SEER) database. Relative survival measures were modelled using non-mixture cure fraction models. Results: The extraction and subsequent period modeling of the dataset resulted in a final total of 11,189 patients and a total of 10,289 years of patient follow-up (between 2001 and 2006). The cure fraction of young adults is expected to be $12 \%$ (95\% Cl 7-16), which is estimated to occur at a minimum time of 10 years post diagnosis. Interpretation: The data, using population-based cure fraction models, indicate that a possibility for cure appears to be present in the young adult population, and occurs at 10 years after diagnosis. Because of the biological and statistical features of this patient population, it is appropriate to study GBM populations using cure fraction models.
\end{abstract}

Copyright $\odot 2012$ S. Karger AG, Basel
(C) 2012 S. Karger AG, Basel

0251-5350/12/0391-0063\$38.00/0

Fax +4161306 1234

E-Mail karger@karger.ch

www.karger.com
Accessible online at: www.karger.com/ned

\section{Introduction}

Glioblastoma multiforme (GBM) remains one of the most deadly cancers with few patients reaching long-term survivor status. Studies are showing that only $2.2 \%$ of patients are estimated to survive 3 years or more after diagnosis of a GBM, a figure that is nevertheless set to increase in the near future due to recent therapeutic advances [1, 2]. However, there are reports that some patients can live for more than 10 years after diagnosis and potentially achieve cure [3-7]. A common feature amongst those patients who live longer than 10 years is that they are typically younger than 40 years at the time of diagnosis.

It is also the age factor that is classically associated with better overall survival (OS) in cancer studies, which is partly due to the fact that older people have a higher background mortality rate or all-cause mortality compared to younger people in the general population [8]. In order to separate the confounding effects of background mortality rates on the relationship between age and OS, a different statistical principle is used, namely that of relative survival (RS). A detailed discussion of RS can be found elsewhere $[9,10]$.

In this report, 'cure' is a term used to describe a feature of patient populations. A population-based cure is said to occur when the overall hazard rate of a group of patients approximates the hazard rate of the matched general population. In other words, if a patient population is found to have the same chance of dying as a member of the gen- 
eral population, that population can be considered cured of their disease. Note that this does not discuss cure on an individual patient basis. More discussions regarding cure fraction modelling is outlined in the work of Verdecchia et al. [11] and Lambert et al. [12, 13].

In this study, the possibility of a population-based cure fraction in patients with GBM is examined using data from the Surveillance, Epidemiology and End-Results (SEER) program. This program allows for the review of large numbers of patients with GBM, as it covers approximately $25 \%$ of the US population. In particular, two features of survival will be described and modelled here. Firstly, we look for a flattening of the RS curve at a percentage above $0 \%$, and this will be modelled using parametric RS non-mixture methods to describe the fraction which are cured (do not die of their disease, or cure fraction). Secondly, we analyse the data to see if the modelled hazard rate of patients with GBM decreases enough to resemble the hazard rate of members of the general population.

\section{Patients and Methods}

The SEER database is a large nationwide database in the United States, which is estimated to cover at present approximately $25 \%$ of the US population with a previously reported $97.7 \%$ case ascertainment rate [14]. In this study, the SEER database was used to identify patients with a GBM (ICD-O-3 9440/3) [15]. To ensure a homogenous sample, the variants giant-cell glioblastoma (9441), gliofibroma (9442/1) and gliosarcoma (9442/3) were excluded from the dataset, as they have different survival profiles $[16,17]$. Individual patient data were obtained from the SEER 17 registries and were matched to SEER-expected mortality tables (which extended until 2006) by year of birth, age, sex and race using the Ederer II technique $[8,18]$. The age criteria of the Adolescent and Young Adult Oncology Progress Review Group were used to define age groups: 'children' (0-15 years of age), 'young adults' (1639 years of age), 'adults' (40-64 years of age) and 'elderly' (65 years of age and older) [19]. Only patients who had radiation and surgery were included in this analysis. Children were not analysed due to the paucity of data in this age category. Finally, the dataset used in the final analysis was modelled using the period approach, which means the data included in this analysis are left truncated and right censored [20].

Defining a Population-Based Cure Fraction in GBM Patients

When a patient group's observed hazard rate (excess and expected hazards combined) returns to that of the general population, that patient group may be considered 'cured' of the disease, as they are just as likely to die as a member of the general population. The mathematical model used here is the non-mixture cure fraction model devised by Lambert et al. [13] in 2007.

$$
\mathrm{S}(\mathrm{t})=\mathrm{S}^{*}(\mathrm{t}) \pi^{\mathrm{Fz}(\mathrm{t})}(1)
$$

Equation (1) describes the estimation of OS using estimates of expected survival rates at time $t$, multiplied by the estimated cure fraction $(\pi)$ of patients at time $t . S^{*}(t)$ is the expected survival obtained from expected mortality tables. $F z(t)$ is the parametric survivor function fit using the Weibull distribution. The Weibull probability distribution is a reasonable assumption to make because the hazard rates of GBM patients tend to approximate this probability distribution [21]. The estimated cure fraction of patients occurs when $t$ equals infinity, which is the asymptote of the Weibull curve.

To model a population-based cure fraction, Kaplan-Meier curves are visually examined to determine if a proportion of patients are not expected to succumb to the disease (a curve which does not end at zero on the y-axis). If the curve 'flattens out' above zero on the y-axis, then a cure is hypothesized to be plausible. Next, a parametric survival curve, in this case a decreasing Weibull model, is fit to the data to estimate the proportion of patients below the asymptote of this curve. The proportion of patients below the asymptote of this curve is termed the cure fraction. The cure time occurs when the excess hazard rate reaches a predefined level, which in this study was 0.01 (or 1\%). The cure time reported here is interpreted as the minimum time a patient must survive before a clinician can assess the patient for a possible presence of a cure.

A requirement in this study was the statistical plausibility of cure. This means that the cure time should occur within a reasonable time frame so as to ensure a cure is plausible within the patient's lifetime. We suggest that a cure time which occurs after that age group's suggested expected survival age in the United States is an argument against the plausibility of cure in that population.

In addition to statistical plausibility, for a cure estimate to be valid, there must be a biological plausibility of a cure. Theoretically, it is thought that if every single tumorigenic GBM cell can be removed or killed during surgery and/or adjuvant therapy the tumor will not recur and the patient may achieve cure. Glioblastomas and other central nervous system tumors have a very low probability of extracranial or distant metastases, and thus dormant distant metastatic tumorigenic cells do not often complicate this disease [22, 23]. However, GBM has a well-known propensity for spreading locally, making resection of the entire tumor at surgery difficult, and this is one of the many reasons why GBM are so difficult to treat and/or cure [24]. Therefore, although this disease is very aggressive, its simplistic nature (lacking metastatic disease and other complicating features) is reason to believe that a biological cure is plausible.

\section{Significance, Hypothesis Testing, Estimation Rates and Assumptions}

The cure fraction, defined as a time interval after diagnosis when the hazard rates of GBM patients resemble that of the general population, is said to occur when the hazard rate in the GBM population is no more than 1 percentile above that of the general population. All statistical analyses were performed on Stata version 11.2 (Stata, College Station, Tex., USA).

\section{Results}

The extraction from the SEER 17 registries yielded a total of 34,560 patients. However, the period approach was applied to the dataset and 15 patients were removed 
Fig. 1. Kaplan-Meier curve for OS (a) and RS curve (b) for all patients followed up between 2001 and 2006. This plot provides little evidence for the plausibility of a cure fraction in adults or elderly patients as the survivor function for these patients all approximate zero at later intervals.

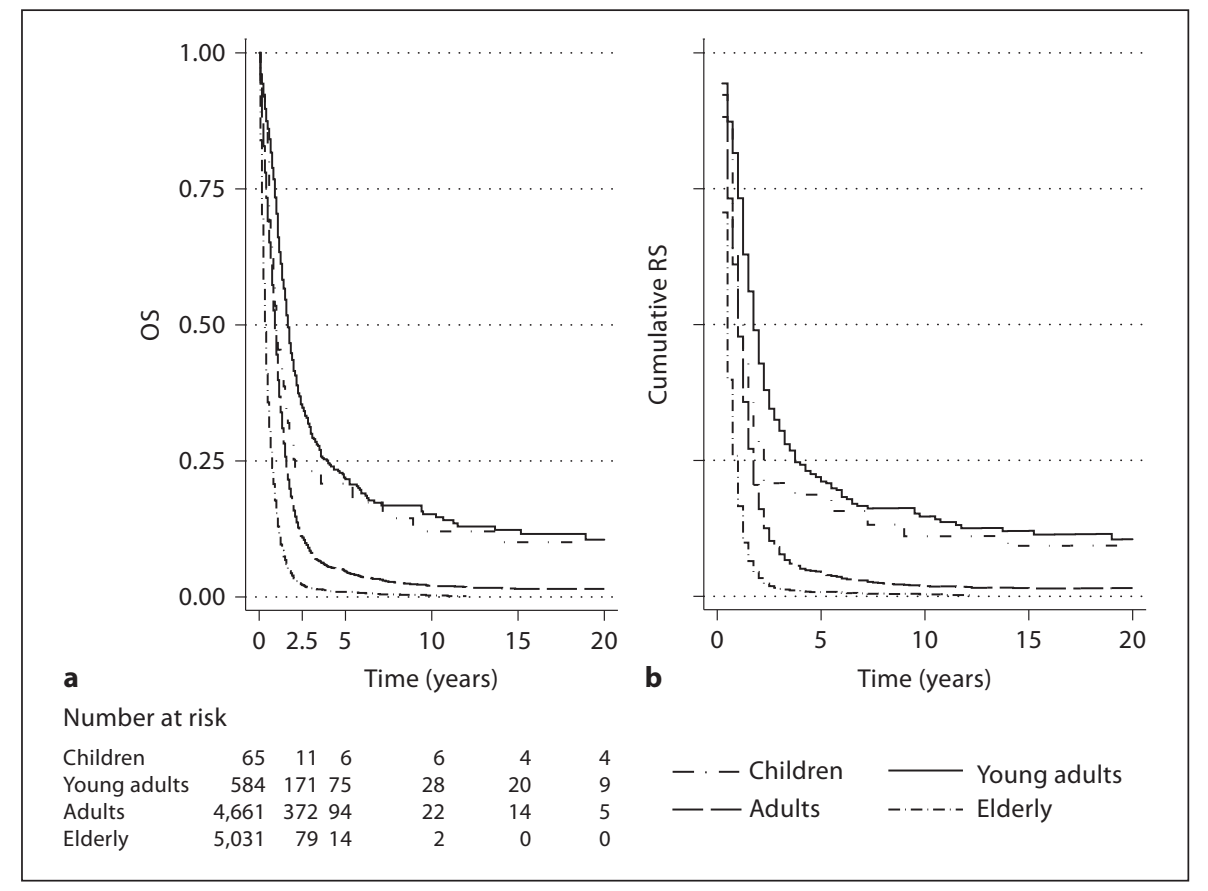

from the analysis due to their coding for a meningeal location $(\mathrm{n}=2)$ and duplicate observations $(\mathrm{n}=13)$. This resulted in a final total of 11,189 patients, 9,570 deaths and a total of 10,289 years of patient follow-up (between 2001 and 2006). The median patient age was 64 years (interquartile range: 21 years). Twenty-five percent of the patients were below 52 years of age, and 25\% were above 73 years. Males formed $58 \%$ of this patient population.

Table 1 describes the patient characteristics of those included in this analysis. The use of the period approach is demonstrated here by the year of diagnosis rows showing few patients being diagnosed further away from 2001. For a detailed examination of treatment patterns see Barnholtz-Sloan et al. [25].

\section{Cure Time and Cure Fraction}

The cure fraction was modeled only in young adults because the presence of a possible cure did not appear plausible for the other age groups (fig. 1). The estimation converged after 7 iterations, and resulted in an estimated $12 \%$ of young adults achieving cure $(95 \%$ confidence interval: 7-16). The estimated hazard rate reached the threshold of being only $1 \%$ greater than that of the hazard rate of the general population at an estimated 9.8 years after diagnosis, which implies that hazard rates approximate those of the general population (or excess hazard rates return to 1\%) approximately 10 years after diagnosis and within the expected lifetime of this population.
Table 1. Characteristics of the patients receiving radiation and surgery for the treatment of GBM followed up between 2001 and 2006

\begin{tabular}{lrr}
\hline Characteristic & $\mathrm{n}$ & $\%$ \\
\hline Male & 3,827 & 60 \\
Female & 2,560 & 40 \\
Age category & 54 & 1 \\
$\quad$ Children & 582 & 9 \\
$\quad$ Young adults & 3,468 & 54 \\
$\quad$ Adults & 2,283 & 36 \\
$\quad$ Elderly & 23 & $<1$ \\
Year of diagnosis & 97 & 2 \\
$\quad$ 1973-1985 & 6,267 & 98 \\
$\quad$ 1986-1996 & 71 & 1 \\
$\quad$ 1997-2008 & 91 & 1 \\
Radiation sequence & 42 & 1 \\
$\quad$ Other & & \\
$\quad$ Radiation prior to surgery & 6,183 & 97 \\
$\quad$ Radiation before and after surgery & 6,387 & 100 \\
$\quad$ Radiation after surgery & \\
\hline Total &
\end{tabular}

a Unknown and various other forms of radiation.

Figure 2 demonstrates the fit of the model in conjunction with the observed survival of the young adult population, with the asymptote of the curve occurring at $12 \%$, indicating that approximately $12 \%$ of the young adult 
Table 2. Age and survival data of patients followed up between 2001 and 2006 who survived $>10$ years after diagnosis

\begin{tabular}{|c|c|c|c|c|c|}
\hline No. & Age & $\begin{array}{l}\text { Years } \\
\text { survived }\end{array}$ & $\begin{array}{l}\text { Year of } \\
\text { diagnosis }\end{array}$ & $\begin{array}{l}\text { Last year } \\
\text { of follow-up }\end{array}$ & Life-status \\
\hline 1 & 16 & 32 & 1975 & 2007 & alive \\
\hline 2 & 17 & 23 & 1984 & 2007 & alive \\
\hline 3 & 17 & 30 & 1977 & 2007 & alive \\
\hline 4 & 17 & 34 & 1973 & 2007 & alive \\
\hline 5 & 17 & 29 & 1978 & 2007 & alive \\
\hline 6 & 17 & 19 & 1988 & 2007 & alive \\
\hline 7 & 17 & 33 & 1974 & 2007 & alive \\
\hline 8 & 18 & 30 & 1977 & 2007 & alive \\
\hline 9 & 19 & 31 & 1976 & 2007 & alive \\
\hline 10 & 20 & 19 & 1988 & 2007 & alive \\
\hline 11 & 20 & 26 & 1981 & 2007 & alive \\
\hline 12 & 20 & 12 & 1995 & 2007 & alive \\
\hline 13 & 21 & 25 & 1982 & 2007 & alive \\
\hline 14 & 23 & 16 & 1991 & 2007 & alive \\
\hline 15 & 23 & 27 & 1976 & 2003 & dead \\
\hline 16 & 23 & 28 & 1976 & 2004 & dead \\
\hline 17 & 24 & 13 & 1990 & 2003 & dead \\
\hline 18 & 24 & 13 & 1993 & 2006 & dead \\
\hline 19 & 25 & 13 & 1994 & 2007 & alive \\
\hline 20 & 26 & 16 & 1991 & 2007 & alive \\
\hline 21 & 26 & 26 & 1981 & 2007 & alive \\
\hline 22 & 26 & 13 & 1994 & 2007 & alive \\
\hline 23 & 27 & 33 & 1974 & 2007 & alive \\
\hline 24 & 27 & 10 & 1997 & 2007 & alive \\
\hline 25 & 28 & 20 & 1987 & 2007 & alive \\
\hline 26 & 28 & 18 & 1985 & 2003 & dead \\
\hline 27 & 29 & 34 & 1973 & 2007 & alive \\
\hline 28 & 29 & 10 & 1997 & 2007 & alive \\
\hline 29 & 29 & 13 & 1994 & 2007 & alive \\
\hline 30 & 30 & 13 & 1994 & 2007 & alive \\
\hline 31 & 30 & 20 & 1987 & 2007 & alive \\
\hline 32 & 30 & 10 & 1997 & 2007 & alive \\
\hline 33 & 30 & 11 & 1996 & 2007 & alive \\
\hline 34 & 31 & 21 & 1986 & 2007 & alive \\
\hline 35 & 31 & 10 & 1994 & 2004 & dead \\
\hline 36 & 31 & 11 & 1991 & 2002 & dead \\
\hline 37 & 31 & 14 & 1993 & 2007 & alive \\
\hline 38 & 32 & 20 & 1987 & 2007 & alive \\
\hline 39 & 32 & 15 & 1992 & 2007 & alive \\
\hline 40 & 32 & 11 & 1996 & 2007 & alive \\
\hline 41 & 32 & 12 & 1995 & 2007 & alive \\
\hline 42 & 33 & 10 & 1991 & 2001 & alive \\
\hline 43 & 33 & 11 & 1996 & 2007 & alive \\
\hline 44 & 33 & 12 & 1995 & 2007 & alive \\
\hline 45 & 34 & 14 & 1989 & 2003 & alive \\
\hline 46 & 34 & 17 & 1990 & 2007 & alive \\
\hline 47 & 35 & 16 & 1991 & 2007 & alive \\
\hline 48 & 35 & 13 & 1993 & 2006 & dead \\
\hline 49 & 36 & 25 & 1982 & 2007 & alive \\
\hline 50 & 36 & 10 & 1994 & 2004 & dead \\
\hline 51 & 36 & 19 & 1988 & 2007 & alive \\
\hline 52 & 36 & 18 & 1989 & 2007 & alive \\
\hline 53 & 36 & 19 & 1988 & 2007 & alive \\
\hline 54 & 37 & 15 & 1989 & 2004 & dead \\
\hline 55 & 37 & 16 & 1991 & 2007 & alive \\
\hline 56 & 37 & 14 & 1992 & 2006 & dead \\
\hline 57 & 38 & 17 & 1990 & 2007 & alive \\
\hline 58 & 38 & 10 & 1997 & 2007 & alive \\
\hline 59 & 38 & 11 & 1996 & 2007 & alive \\
\hline 60 & 39 & 11 & 1996 & 2007 & alive \\
\hline 61 & 39 & 10 & 1997 & 2007 & alive \\
\hline 62 & 39 & 12 & 1995 & 2007 & alive \\
\hline
\end{tabular}

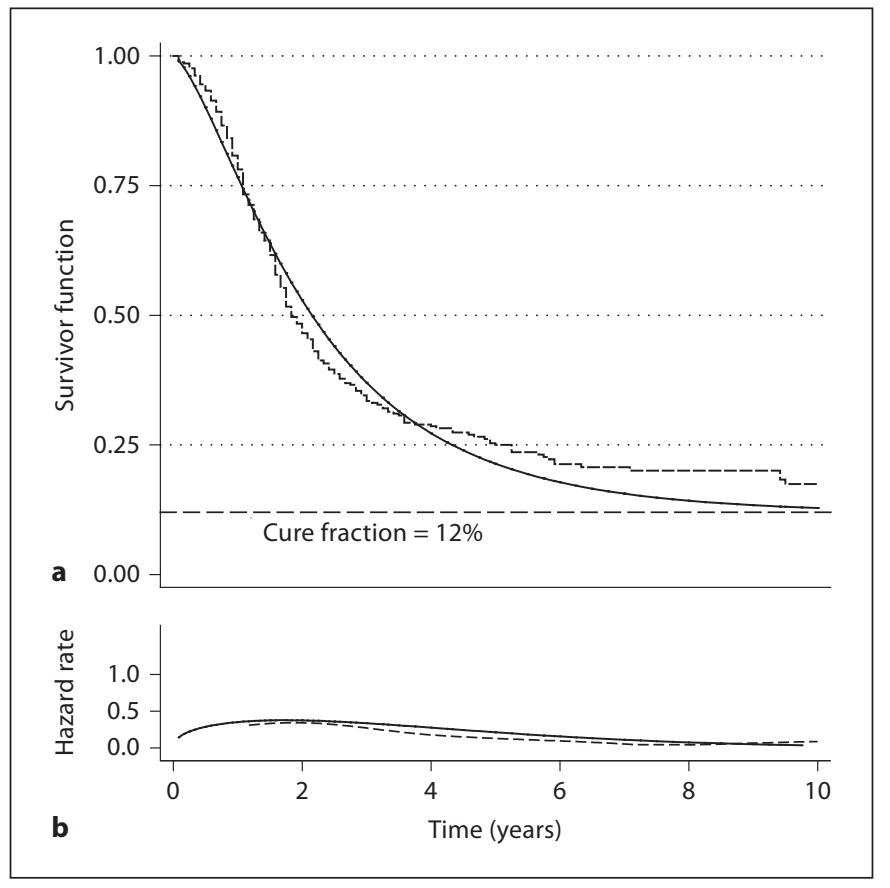

Fig. 2. a Observed OS (dotted line) versus estimated cure fraction model (smooth gray curve) for young adults only. Adults and the elderly were not modelled as no plausibility of cure is found for these groups (fig. 1). The cure line at $12 \%$ is the estimated survival proportion at $t=\boldsymbol{c}$. $\mathbf{b}$ This is the fit of the cure fraction model with a Weibull assumption for hazards plotted on the hazard scale. The solid line is the estimated model and the dotted line is the actual smoothed hazard rate.

population receiving radiation and surgery while suffering from a GBM will not succumb to the disease. Altogether, 62 patients of the young adult population included in this analysis were noted to have survived past 10 years; the details are shown in table 2. Figure 1 demonstrates that only 20 patients were at risk at 10 years, yet 62 patients included in this analysis survived $>10$ years. This is because of the left truncation or late entry of patients into the lifetable causes some patients to enter into the study period after 10 years.

\section{Discussion}

A small proportion of the young adult population appear to achieve a cure (at most 12\%) from a populationbased perspective. While these data cannot be interpreted as suggesting that a cure is impossible for adult and elderly groups, it appears that achieving a populationbased cure (as described here) is highly unlikely for these 
groups (fig. 1). If the adults and elderly were to be modeled, the cure time would be earlier than 10 years, and therefore it is appropriate to use this cure time for other age groups.

When reviewing this work, it appears that of the 584 young adults in the database, we should expect 70 patients to be alive or in the at-risk population at the 10-year mark shown in figure 1, if $12 \%$ of patients will not die of their disease. This is because the data used here are censored data, which means there are patients who are still alive, but have not reached the 10 -year mark yet.

The use of cure fractions with and without the use of RS data has been used by several groups, most commonly for breast and colon cancer studies [11, 12, 26, 27]. From a biological and statistical standpoint, we suggest that the cure fraction modelling is more appropriate to modelling of GBM survival than that of cancers of other locations. As mentioned previously, the biological behaviour of GBM favours a local disease with a low incidence of distant metastatic disease (although a very aggressive local disease) $[22,23]$. Statistically, the excess mortality of the GBM population returns to very low levels after diagnosis, implying that a cure can occur within the lifetime of individuals (10 years). High levels of excess mortality many years after diagnosis is often what causes difficulty in validating cure fraction models from other diseases, such as colon, breast and salivary tumors $[12,28,29]$. The young adult GBM population's excess mortality approximates zero, or overall mortality approximates that of the general population of young adults within 10 years after the initial diagnosis, which is an argument for the plausibility of a population-based cure in this subset of patients.

The plausibility of cure time presented here must be supported by individual patient experiences. The majority of patients reported in case reports and case series that are thought to have been cured (from a clinical perspective) are in the younger age categories, which is consistent with the results of this study $[3-6,30]$. Vertosick and Selker [31] published a series of patients treated at their institution and suggested that cure may occur in GBM patients after 4 years of survival due to the low rates of recurrence ( 1 of 22 patients with GBM and high-grade gliomas). In contrast to this, Bahr et al. [7] described 3 patients who actually recurred after 10 years. It should be noted that only 1 of these patients was a young adult, and was 1 year away from being considered an adult. This latter study also included 4 patients who survived past 10 years without a recurrence, of which 3 were young adults, and the final patient only 3 years past being considered a young adult at diagnosis (42 years old). The published case studies of patients with prolonged survival demonstrate that those who may achieve cure (from a clinical perspective) tend to be young adults, supporting the proposal that a cure is most plausible for young adults.

\section{Applications}

This data analysis provides the patient, clinician and scientist with a valuable time point during follow-up. For patients, once they reach the 10-year mark they can be reassured that their risk of death is very close to that of the general population, which is small especially if they are in the young adult category. For the clinician, the 10year mark is a point which is appropriate to do a full clinical and radiological review of the patient to see if this patient has achieved a cure. For the scientist, patients who survive 10 years mark a very special subset of patients who have properties that are yet to be described and associated with prolonged survival. Because these data are based on an observational registry dataset, the analysis can only provide information on important time points during the follow-up, and no information on the effects of different treatments offered to these patients.

\section{Cautions and Limitations}

The distinction that needs to be made by the reader is that a cure is determined by patient-specific factors, such as clinical and radiological findings (individual patientbased perspective), and not a certain amount of time survived after diagnosis. A key feature in the interpretation of the population-based cure time reported here is that it is the minimum time a patient must survive before a clinician can suggest that a patient may have been cured, rather than interpreted as all patients who survive past this time point are cured. Thus, any decision to terminate or make changes to follow-up schedules should be made primarily on individual, patient-based information such as clinical and radiological findings.

The statistical methods used in this analysis to produce the cure fraction estimate rely on underlying probability distributions to explain an underlying process. Depending on the shape and magnitude of the Weibull curve, one can make deductions about survival or hazard probabilities throughout follow-up, much like one can deduce that $68.2 \%$ of observations are within 1 standard deviation (SD) of the mean when describing data that are normally distributed (which is also a process), or that $12 \%$ of patients are expected to achieve a possible cure. Therefore, an assumption made in this study is that the survival distributions follow a Weibull distribution, which is 
reasonable given the results of other studies [21]. Hence, it is important to note that the parametric model presented here serves to describe an underlying process that occurs in populations of patients diagnosed as suffering from a GBM.

Other studies have shown that long-term survival (and potentially cure) can be due to misclassification of tumor histology at the time of diagnosis $[1,32]$. This questions the validity of the $12 \%$ cure fraction and the cure time reported here, as a proportion of patients that would be included in this may actually be diagnosed with lowergrade gliomas with better survival profiles. To estimate accurate and unbiased long-term survival and cure estimates, case deletion of only long-term survivors with misdiagnosed or misclassified tumors seems not to be appropriate because it leads to downwardly biased longterm survival estimates because of uneven case deletion. Therefore, investigators should review each included sample rather than only a subset of tumors in order to produce survival estimates. This would have been difficult given the size of the cohort in this study. While the estimates presented here remain valid representations of what occurs in the US population diagnosed with GBM (more specifically the SEER registries), one of the many reasons a population may have achieved cure may be due to the initial misclassification of tumor type, with all patients being exposed to this possibility.

\section{Conclusion}

The data, using population-based cure fraction models, indicate that a possibility for cure appears to be present in the young adult population, and occurs 10 years after diagnosis. Because of the biological and statistical features of this patient population, it is appropriate to study GBM populations using cure fraction models.

\section{Acknowledgements}

The first author would like to thank Assoc. Prof. Elmer Villanueva for his continued mentorship. We would all like to thank Assoc. Prof. Damien Jolley for his wisdom, Ms. Laetitia Smoll and the anonymous peer reviewers for their time and effort for improving the manuscript.

\section{References}

$\checkmark 1$ Scott JN, Rewcastle NB, Brasher PM, Fulton D, MacKinnon JA, Hamilton M, Cairncross JG, Forsyth P: Which glioblastoma multiforme patient will become a long-term survivor? A population-based study. Ann Neurol 1999;46:183-188.

-2 Stupp R, Mason WP, van den Bent MJ, Weller M, Fisher B, Taphoorn MJ, Belanger K, Brandes AA, Marosi C, Bogdahn U, Curschmann J, Janzer RC, Ludwin SK, Gorlia T, Allgeier A, Lacombe D, Cairncross JG, Eisenhauer E, Mirimanoff RO: Radiotherapy plus concomitant and adjuvant temozolomide for glioblastoma. N Engl J Med 2005; 352:987-996.

- 3 Salvati M, Cervoni L, Artico M, Caruso R, Gagliardi FM: Long-term survival in patients with supratentorial glioblastoma. J Neurooncol 1998;36:61-64.

4 Cervoni L, Celli P, Salvati M: Long-term survival in a patient with supratentorial glioblastoma: clinical considerations. Ital J Neurol Sci 1998; 19:221-224

5 Bucy PC, Oberhill HR, Siqueira EB, Zimmerman HM, Jelsma RK: Cerebral glioblastomas can be cured! Neurosurgery 1985;16: $714-717$.

-6 Chandler KL, Prados MD, Malec M, Wilson CB: Long-term survival in patients with glioblastoma multiforme. Neurosurgery 1993 32:716-720, discussion 720 .
7 Bahr O, Herrlinger U, Weller M, Steinbach JP: Very late relapses in glioblastoma longterm survivors. J Neurol 2009; 256:17561758.

8 Surveillance, Epidemiology and End Results (SEER) Program, SEER*Stat Database: Mortality - all COD, aggregated with state, total U.S. (1969-2006), <katrina/rita population adjustment $>$ underlying mortality data provided by NCHS (http://www.Cdc.Gov/nchs); in Cancer Statistics Branch (ed): Surveillance Research Program. Bethesda, National Cancer Institute, 2010

9 Swaminathan R, Brenner H: Stastistical methods for cancer survival analysis. IARC Sci Publ 2011;162:7-13.

10 Sarfati D, Blakely T, Pearce N: Measuring cancer survival in populations: relative survival vs cancer-specific survival. Int J Epidemiol 2010;39:598-610.

11 Verdecchia A, De Angelis R, Capocaccia R, Sant M, Micheli A, Gatta G, Berrino F: The cure for colon cancer: results from the EUROCARE study. Int J Cancer 1998;77:322329.

12 Lambert PC, Dickman PW, Osterlund P, Andersson T, Sankila R, Glimelius B: Temporal trends in the proportion cured for cancer of the colon and rectum: a populationbased study using data from the Finnish Cancer Registry. Int J Cancer 2007;121: 2052-2059.
13 Lambert PC, Thompson JR, Weston CL, Dickman PW: Estimating and modeling the cure fraction in population-based cancer survival analysis. Biostatistics 2007;8:576-594.

14 Zippin C, Lum D, Hankey BF: Completeness of hospital cancer case reporting from the SEER Program of the National Cancer Institute. Cancer 1995;76:2343-2350.

15 International Classification of Diseases for Oncology, ed 3. Geneva, World Health Organization, 2011.

16 Kozak KR, Mahadevan A, Moody JS: Adult gliosarcoma: epidemiology, natural history, and factors associated with outcome. Neuro Oncol 2009;11:183-191.

17 Kozak KR, Moody JS: Giant cell glioblastoma: a glioblastoma subtype with distinct epidemiology and superior prognosis. Neuro Oncol 2009;11:833-841.

18 Surveillance, Epidemiology and End Results (SEER) Program: SEER 17 regs research data 1973-2007; in Cancer Statistics Branch (ed): Surveillance Research Program. Bethesda, National Cancer Institute, 2011.

19 Albritton KCM, Caligiuri M, Anderson B, Nichols C, Ulman D: Closing the Gap: Research and Care Imperatives for Adolescents and Young Adults with Cancer. Report of the Adolescent and Young Adult Oncology Progress Review Group. Bethesda, National Cancer Institute, 2006. 
20 Brenner H, Gefeller O: An alternative approach to monitoring cancer patient survival. Cancer 1996;78:2004-2010.

-21 Polley MY, Lamborn KR, Chang SM, Butowski N, Clarke JL, Prados M: Conditional probability of survival in patients with newly diagnosed glioblastoma. J Clin Oncol 2011;29:4175-4180.

-22 Smoll NR, Villanueva EV: The epidemiology of extraneural metastases from primary brain, spinal cord, and meningeal tumors. Neurosurgery 2010;67:E1470-E1471.

-23 Varan A, Sari N, Akalan N, Soylemezoglu F, Akyuz C, Kutluk T, Buyukpamukcu M: Extraneural metastasis in intracranial tumors in children: the experience of a single center. J Neurooncol 2006;79:187-190.

-24 Salazar OM, Rubin P: The spread of glioblastoma multiforme as a determining factor in the radiation treated volume. Int J Radiat Oncol Biol Phys 1976;1:627-637.
25 Barnholtz-Sloan JS, Williams VL, Maldonado JL, Shahani D, Stockwell HG, Chamberlain M, Sloan AE: Patterns of care and outcomes among elderly individuals with primary malignant astrocytoma. J Neurosurg 2008;108:642-648.

26 Woods LM, Rachet B, Lambert PC, Coleman MP: 'Cure' from breast cancer among two populations of women followed for 23 years after diagnosis. Ann Oncol 2009;20:13311336.

27 Gamel JW, Meyer JS, Feuer E, Miller BA: The impact of stage and histology on the longterm clinical course of 163,808 patients with breast carcinoma. Cancer 1996;77:14591464.

28 Brenner H, Hakulinen T: Are patients diagnosed with breast cancer before age 50 years ever cured? J Clin Oncol 2004;22:432-438.
29 Tai P, Yu E, Cserni G, Vlastos G, Royce M, Kunkler I, Vinh-Hung V: Minimum followup time required for the estimation of statistical cure of cancer patients: verification using data from 42 cancer sites in the SEER database. BMC Cancer 2005;5:48.

30 Sperduto CM, Chakravarti A, Aldape K, Burger P, Papermaster GB, Sperduto P: Twenty-year survival in glioblastoma: a case report and molecular profile. Int J Radiat Oncol Biol Phys 2009;75:1162-1165.

31 Vertosick FT Jr, Selker RG: Long-term survival after the diagnosis of malignant glioma: a series of 22 patients surviving more than 4 years after diagnosis. Surg Neurol 1992;38:359-363.

32 Morita M, Rosenblum MK, Bilsky MH, Fraser RA, Rosenfeld MR: Long-term survivors of glioblastoma multiforme: clinical and molecular characteristics. J Neurooncol 1996; 27:259-266. 